\title{
sciendo
}

\section{MANIPULATION OF RUMEN FERMENTATION AND METHANE GAS PRODUCTION BY PLANT SECONDARY METABOLITES (SAPONIN, TANNIN AND ESSENTIAL OIL) - A REVIEW OF TEN-YEAR STUDIES}

\author{
Saied Jafari ${ }^{1}$, Mahdi Ebrahimi ${ }^{1,2}$, Yong M. Goh ${ }^{1,3}$, Mohamed A. Rajion ${ }^{1}$, Mohamed F. Jahromi ${ }^{4}$, \\ Wisam S. Al-Jumaili ${ }^{1,5}$ \\ ${ }^{1}$ Department of Veterinary Preclinical Sciences, Faculty of Veterinary Medicine, \\ Universiti Putra Malaysia, 43400 Serdang, Selangor, Malaysia \\ ${ }^{2}$ Department of Plant Sciences \& Biotechnology, Faculty of Life Sciences \& Biotechnology, \\ Shahid Beheshti University, Tehran, Iran \\ ${ }^{3}$ Institute of Tropical Agriculture, Universiti Putra Malaysia, 43400 Serdang, Selangor, Malaysia \\ ${ }^{4}$ Agriculture Biotechnology Research Institute of Iran (ABRII), East and North-East Branch, \\ P.O.B. 91735 844, Mashhad, Iran \\ ${ }^{5}$ Department of Animal Resources, College of Agriculture, University of Al-Qassim Green, \\ Babylon, 51013 Al-Qassim, Iraq \\ •Corresponding author: mehdiebrahimii@gmail.com
}

\begin{abstract}
A wide range of plant secondary metabolites (PSM) have been shown to have the potential to modulate the fermentation process in the rumen. The use of plants and plant extracts as natural feed additives has become an interesting topic not only among nutritionists but also other scientists. Although a large number of phytochemicals (e.g. saponins, tannins and essential oils) have recently been investigated for their methane $\left(\mathrm{CH}_{4}\right)$ reduction potential, there have not yet been major breakthroughs that could be applied in practice. However, the effectiveness of these PSM depends on the source, type and the level of their presence in plant products. The aim of the present review was to assess ruminal $\mathrm{CH}_{4}$ emission through a comparison of integrating related studies from published papers, which described various levels of different PSM sources being added to ruminant feed. Apart from $\mathrm{CH}_{4}$, other related rumen fermentation parameters were also included in this review.
\end{abstract}

Key words: rumen, methane, fermentation, plant secondary metabolite

Methanogenesis is one of the important means to remove $\mathrm{H}_{2}$ (produced as a result of the carbohydrate decomposition) from the rumen (Mihaela et al., 2014). The microorganisms that produce methane $\left(\mathrm{CH}_{4}\right)$ as the end product of their respiration are called methanogens and the process through which methanogens produce $\mathrm{CH}_{4}$ is called methanogenesis.

Methanogenesis is energy consuming and accounts for almost $20 \%$ of gross energy intake of the animals (Bhatta et al., 2012). This energy is eventually wasted in 
the form of $\mathrm{CH}_{4}$ (Johnson and Johnson, 1995). Beside energy spoilage through the $\mathrm{CH}_{4}$ formation, it is 23 times higher than $\mathrm{CO}_{2}$ in trapping the atmospheric heat and it is considered as a greenhouse gas $(\mathrm{GHG})$ which plays a pivotal role in the global warming with negative consequences on the worldwide environment (Bodas et al., 2012). In the ruminant, methanogenesis occurs both in the rumen and in the hindgut, but the majority of the $\mathrm{CH}_{4}$ originates from the rumen in which $\mathrm{CH}_{4}$ takes up nearly $90 \%$ of the total $\mathrm{CH}_{4}$ production of ruminants (Kumar et al., 2013); therefore, plenty of research is needed to find a suitable feed alternative to mitigate rumen $\mathrm{CH}_{4}$ production for better and greener environment, and eventually, better livestock production as well.

\section{Dietary strategies to reduce rumen methanogenesis}

Production of $\mathrm{CH}_{4}$ is an intrinsic process of ruminal fermentation as mentioned earlier and suppressing or abating its formation is a big challenge. Many types of $\mathrm{CH}_{4}$ inhibitors have been repeatedly experimented to mitigate the production of enteric $\mathrm{CH}_{4}$ (Patra, 2014).

However, most of them have shown negative effects on rumen fermentation characteristics when added at high doses to achieve effective $\mathrm{CH}_{4}$ inhibition (Patra and Yu, 2013). In addition, some of these inhibitors are toxic to animals (Patra, 2012). Meanwhile, contemporary consumer demands orient towards the use of phytochemicals which are natural products to alter rumen fermentation. Plants produce a diverse array of plant secondary metabolites (PSM), which are not biologically involved in primary biochemical processes such as plant growth, development and reproduction (Bhatta et al., 2015). Besides, more than 200,000 defined PSM structures have been identified (Hartmann, 2007). The majority of PSM can generally be classified into three groups; saponins, tannins and essential oils (EO).

Saponins are a class of PSM that possess a great complexity in their structures as well as their biological activities (Jayanegara et al., 2014). Basically, chemical structure of saponins consists of a sugar moiety (e.g. glucose, galactose, glucuronic acid) which is linked to a hydrophobic aglycone or sapogenin (Francis et al., 2002). Accordingly, the biological activity of saponins depends on the nature, number and sequence of the sugars in the structures (Chwalek et al., 2006).

Tannins are complex mixtures of individual compounds having molecular weights ranging from 500 to over 3000 (gallic acid esters) and up to 20000 (proanthocyanidins) which are usually subdivided into two groups based on the chemical structure: hydrolyzed tannin (HT) and condensed tannin (CT) (Bhatta et al., 2009).

Widely occurring in plants and animals, EO may consist of volatile constituents of terpenoid or non-terpenoid origin (Cieslak et al., 2013). Under this group, hundreds of large or small molecules can be present, consisting of hydrocarbons and their oxygenated derivatives. The composition of EO is usually characteristic for the particular plant species and responsible for its fragrance (Cieslak et al., 2013).

The effectiveness of PSM (e.g. saponins, tannins and EO) has been screened in in vitro and in vivo studies in the last few decades. Our purpose for the current review is to provide deeper insights into the use of PSM to reduce $\mathrm{CH}_{4}$ emission from ruminants and consequently to reduce the impact of global warming. 


\section{Effect of saponins on rumen methanogenesis and fermentation characte- ristics}

Review of recent studies about the effects of saponin sources on rumen $\mathrm{CH}_{4}$ and fermentation parameters are shown in Tables 1 and 2, respectively. Saponins or saponin-like substances have been reported to suppress $\mathrm{CH}_{4}$ production and to modulate rumen fermentation patterns (Patra and Yu, 2012, 2013, 2014 a, b and 2015). In a series of in vitro studies by us, the addition of papaya leaf (a saponin-rich source), methanolic extract of papaya leaf and different solvent extracts of papaya leaf reduced the $\mathrm{CH}_{4}$ production by 37,34 and $30 \%$ as compared to control group, respectively (Jafari et al., $2016 \mathrm{a}$, b and c). As expected, reduced $\mathrm{CH}_{4}$ production in our study was accompanied by reduced acetic/propionate ratio providing the sink for metabolic $\mathrm{H}_{2}$ during rumen fermentation. Consistently, Wanapat et al. (2014) reported the reduction of $\mathrm{CH}_{4}$ by the inclusion of mangosteen peel powder (saponin-rich fruit) without a negative effect on dry matter intake, ruminal $\mathrm{pH}$, total volatile fatty acid and $\mathrm{NH}_{3} \mathrm{~N}$ concentration while increasing propionic concentration and decreasing acetic-propionic ratio in swamp buffaloes. Cieslak et al. (2013) reported that there was some ambiguity in the literature concerning the mechanism of action of saponins to reduce methanogens and methanogenesis. According to Guo et al. (2008), mitigation of methanogenesis using tea saponin resulted from decreased activity of the morA gene (an indicator of the methanogenic activity of the methanogen population), without changing the total methanogen numbers. However, $3 \mathrm{~g}$ /day of tea saponins in sheep diets had no effect on the populations of methanogens (Mao et al., 2010; Zhou et al., 2011). Earlier in vitro research had suggested mitigation of methanogenesis without a reduction in the number of methanogens with the use of saponins from Sapindus saponaria or tea saponins (Hu et al., 2005). However, Jayanegara et al. (2014) reported that saponins decreased $\mathrm{CH}_{4}$ emission due to a lower relative abundance of methanogen population in the presence of the respective substances in the rumen. A combination of nitrate and quillaja saponin (saponin source) was shown to reduce $\mathrm{CH}_{4}$ production by almost $60 \%$ using an in vitro model of rumen cultures (Patra and $\mathrm{Yu}, 2013)$. Patra and Yu (2013) proposed that quillaja saponin functioned as an inhibitor to rumen protozoa, decreased $\mathrm{H}_{2}$ production by protozoa and protozoa-associated methanogens. Patra and $\mathrm{Yu}(2014 \mathrm{a}, \mathrm{b})$ reported that $\mathrm{CH}_{4}$ production was the lowest (45.7\% depression) when combined with other $\mathrm{CH}_{4}$ inhibitors (e.g. sulfate and nitrate).

Some authors have reported an insignificant effect of a saponin-rich source on in vivo $\mathrm{CH}_{4}$ emissions of ruminants (Li and Powers, 2012). In contrast, some studies observed a $\mathrm{CH}_{4}$ reduction in vivo on the addition of saponin-rich sources into basal diets (Wang et al., 2011; Zhou et al., 2011). Thus, like in the in vitro studies, the effects of saponins on in vivo $\mathrm{CH}_{4}$ emission from ruminants have produced contrasting results. According to some studies (e.g. Bodas et al., 2012), the duration of saponin administration and the ratio of forage to concentrate may have a significant influence on their effectiveness. Nonetheless, in addition to suppressing $\mathrm{CH}_{4}$ production, the use of saponins may also confer nutritional benefits as they might increase microbial protein synthesis due to inhibition of protozoa, and might increase the fiber-degrading bacteria and fungi in the rumen, which is beneficial for utilizing in low-qualitybased diets (Rira et al., 2015). 


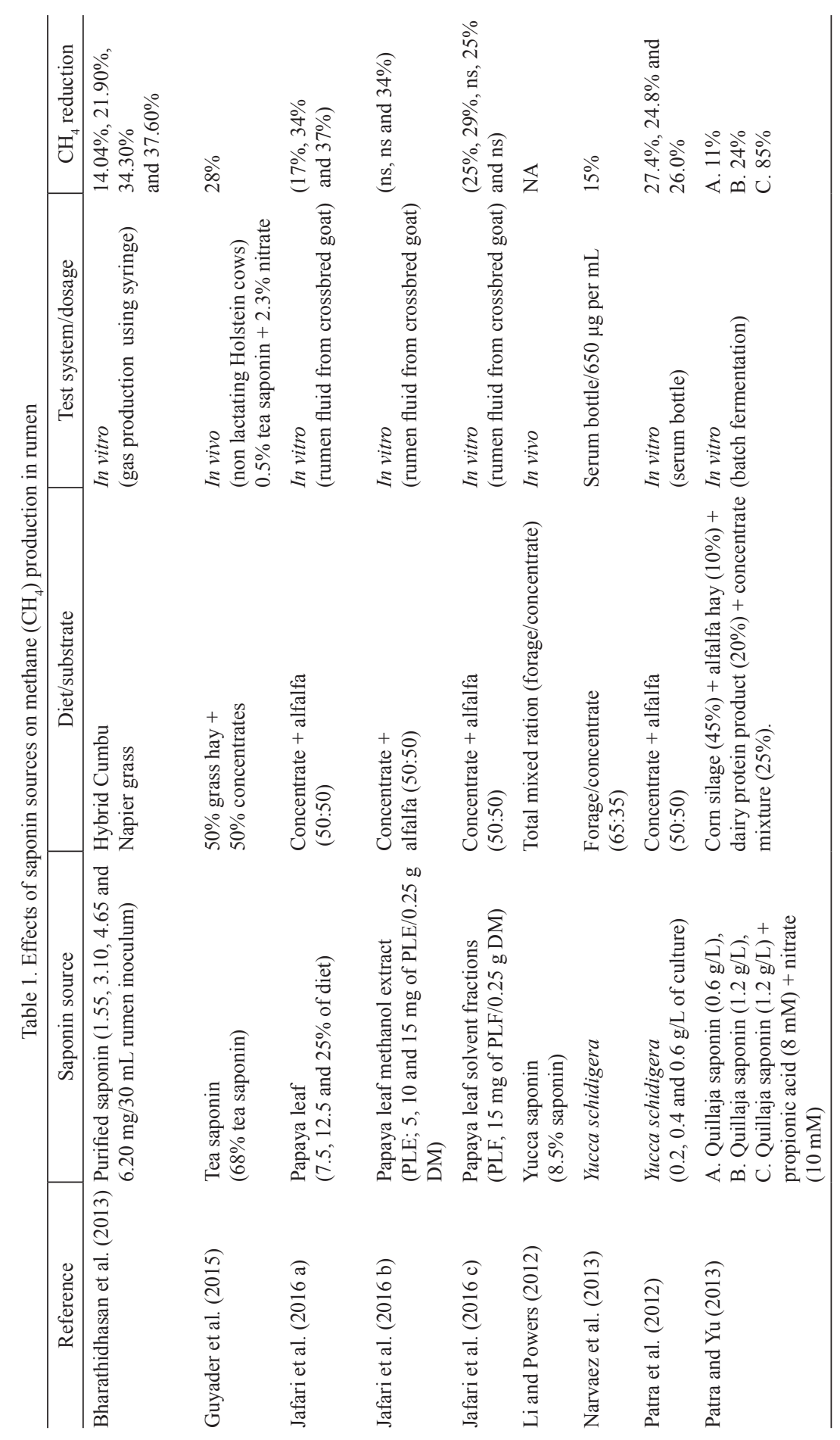




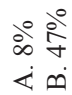

i̊ำ i̊ ì

«ं ம்

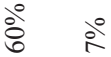

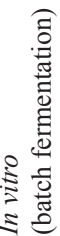

ণ্ণ?

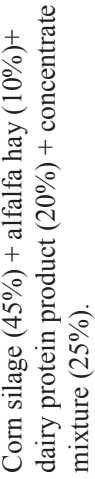

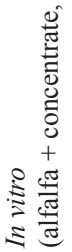

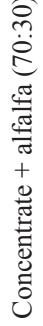

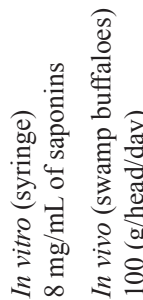

$>$

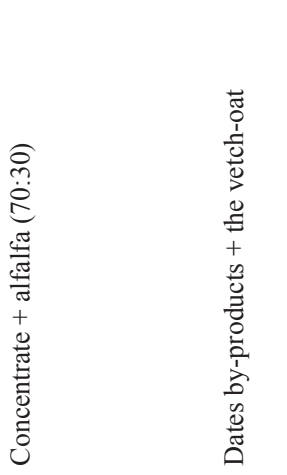

Эิ

$\stackrel{0}{\varrho}$

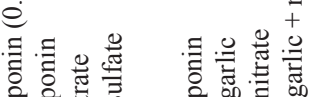

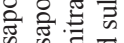

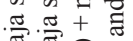

.

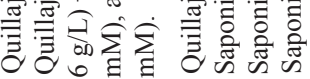

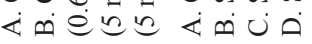

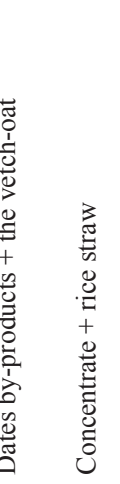

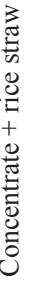

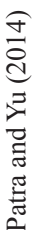

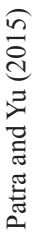

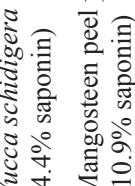

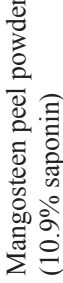




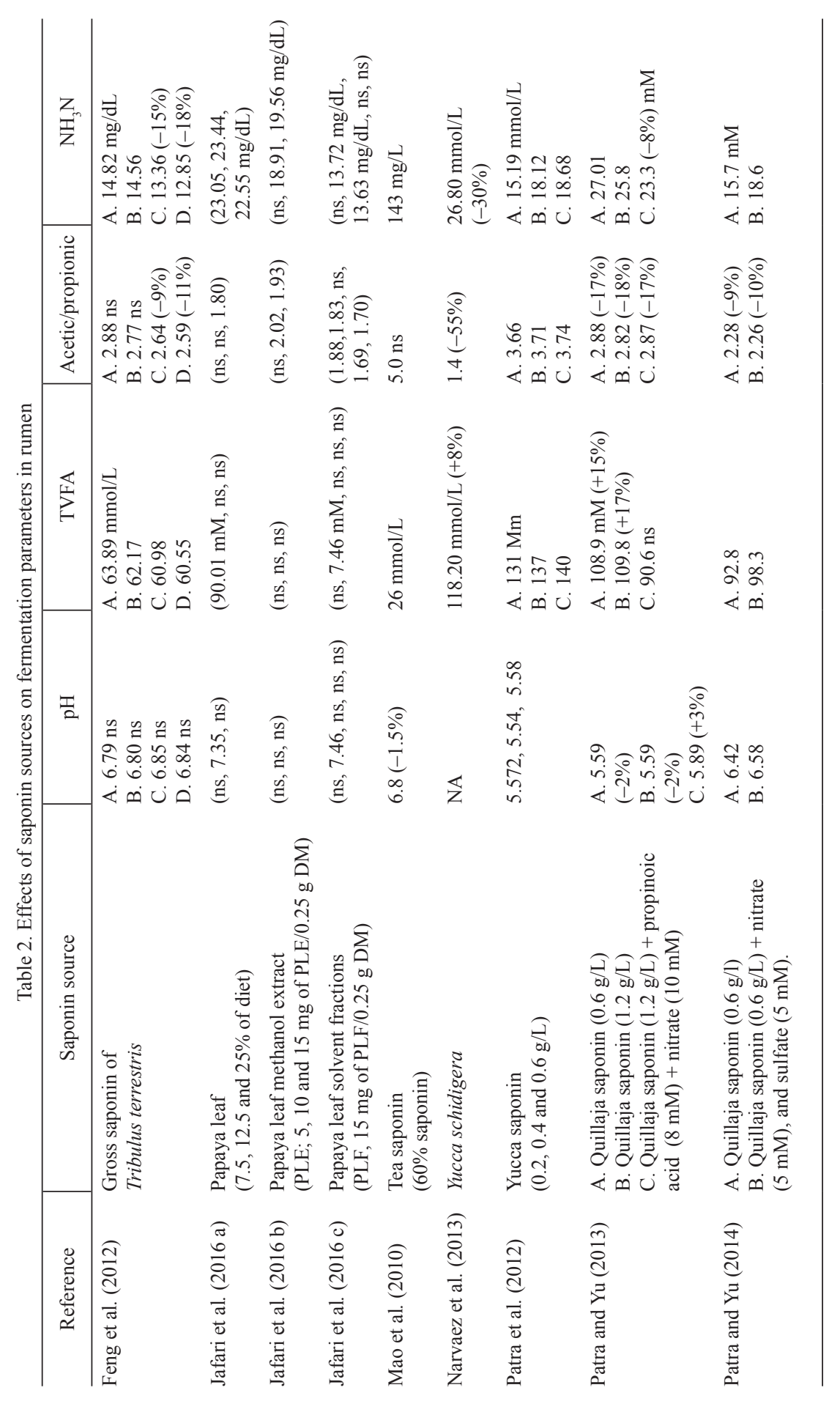




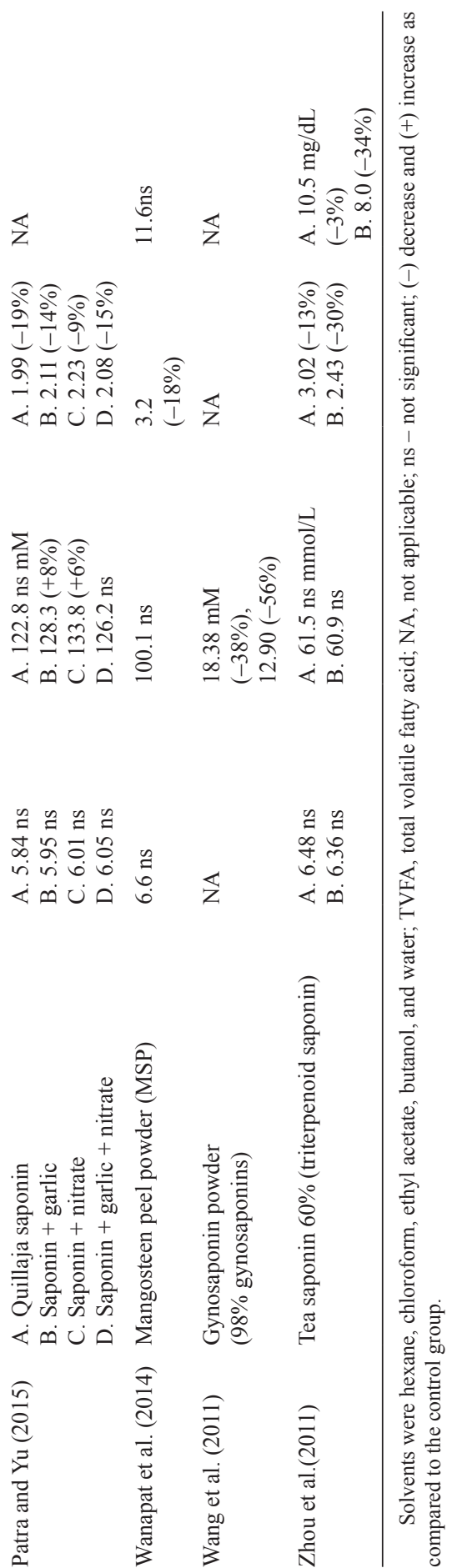




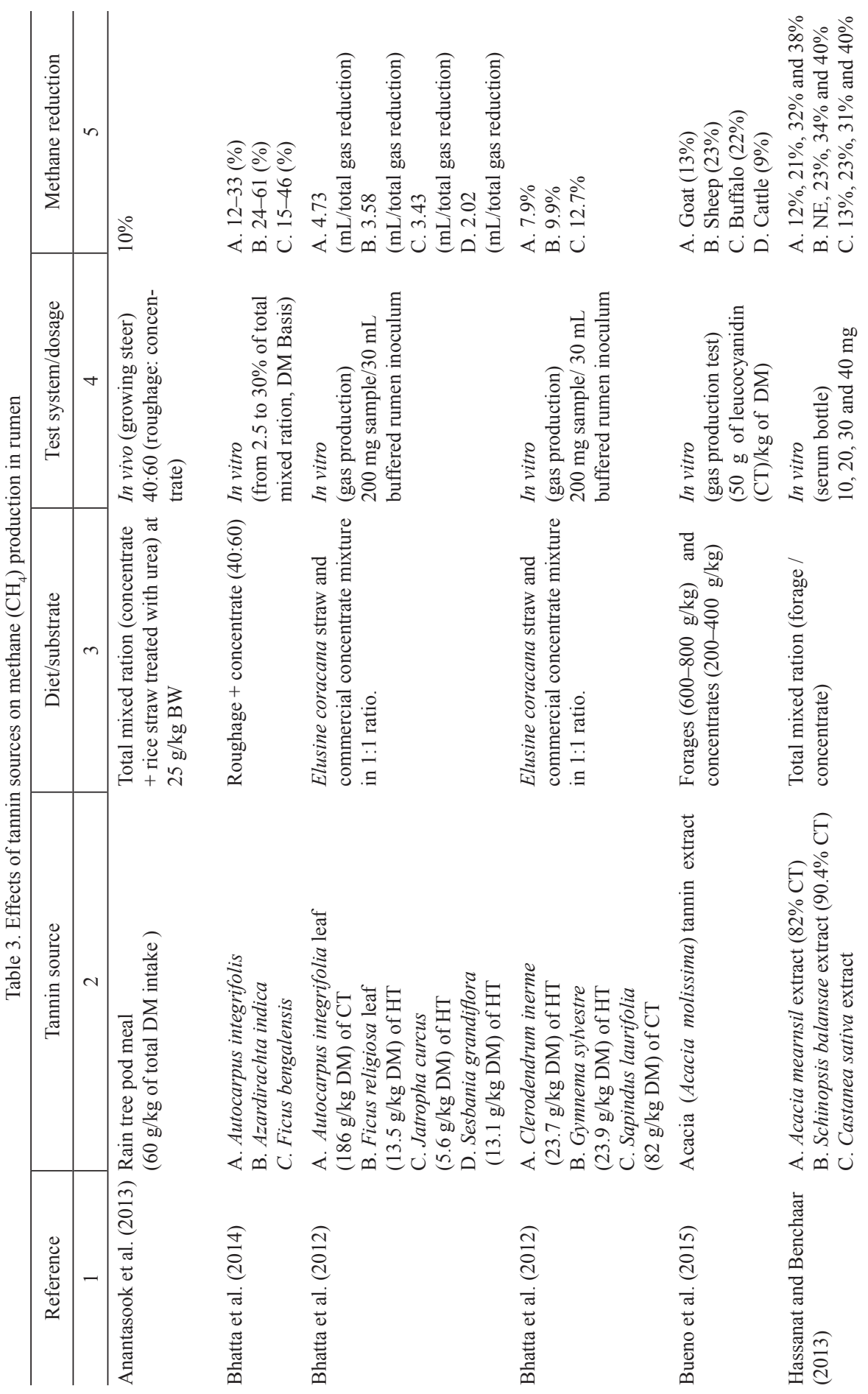




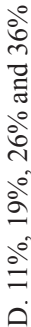

ठे̀े iें

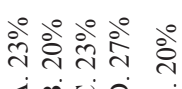

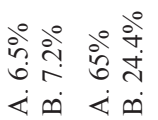

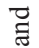

४⿻尸丿十

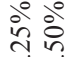
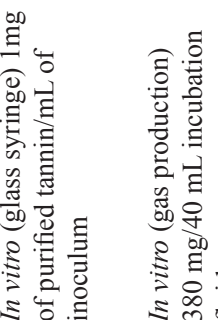

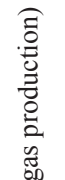

苞艺

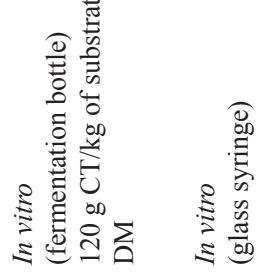

至苗.

芴定

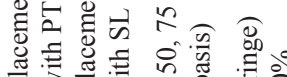

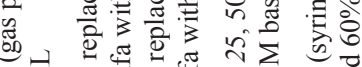

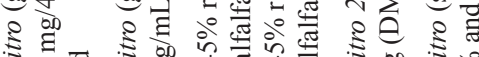

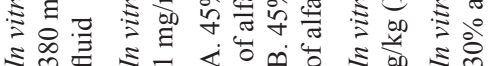
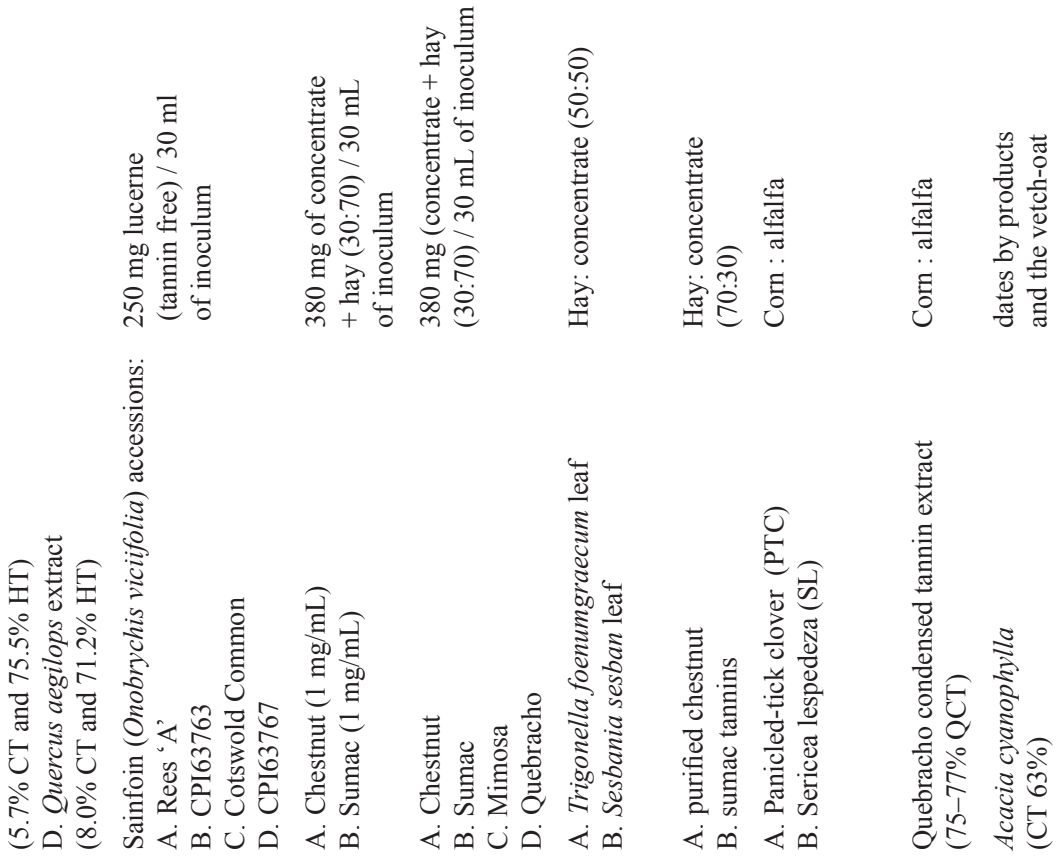

告

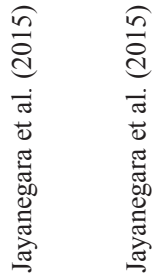

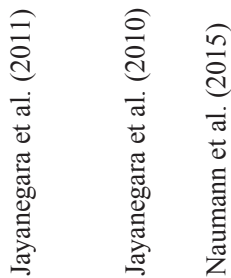

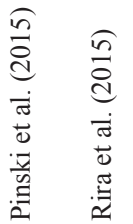




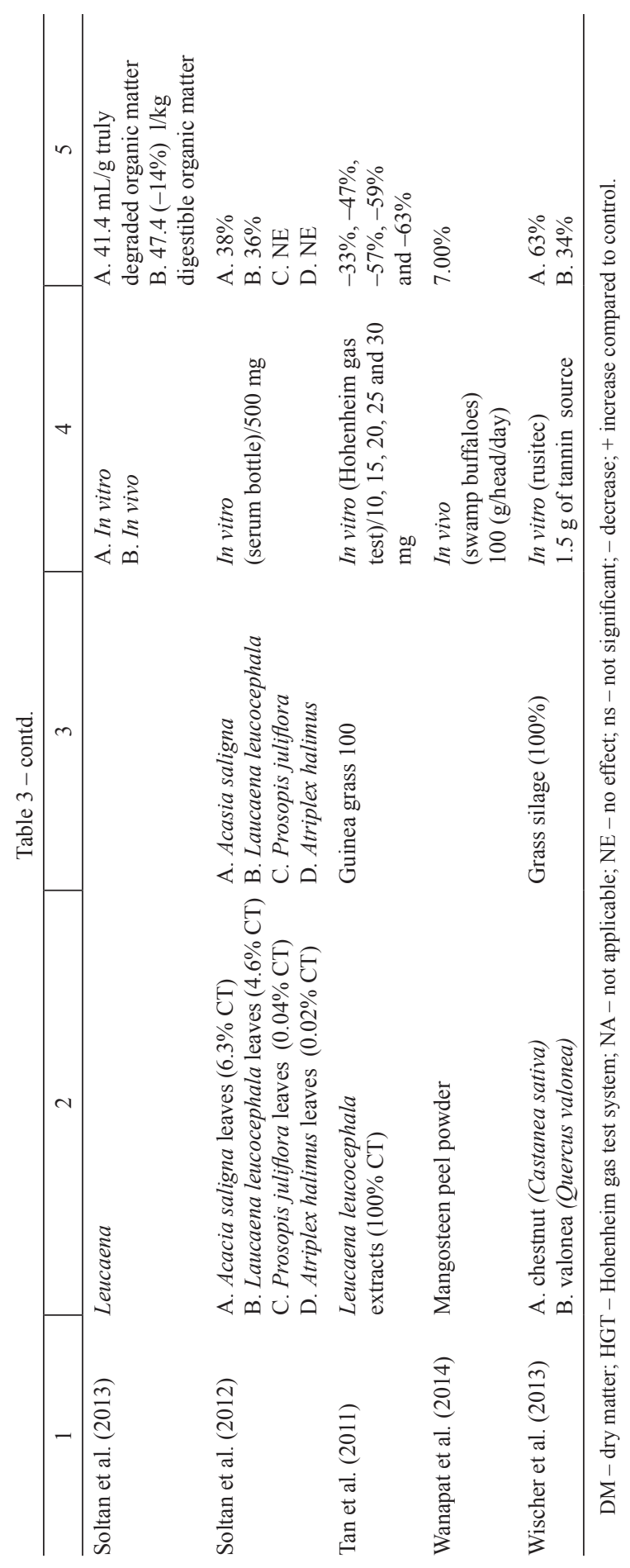




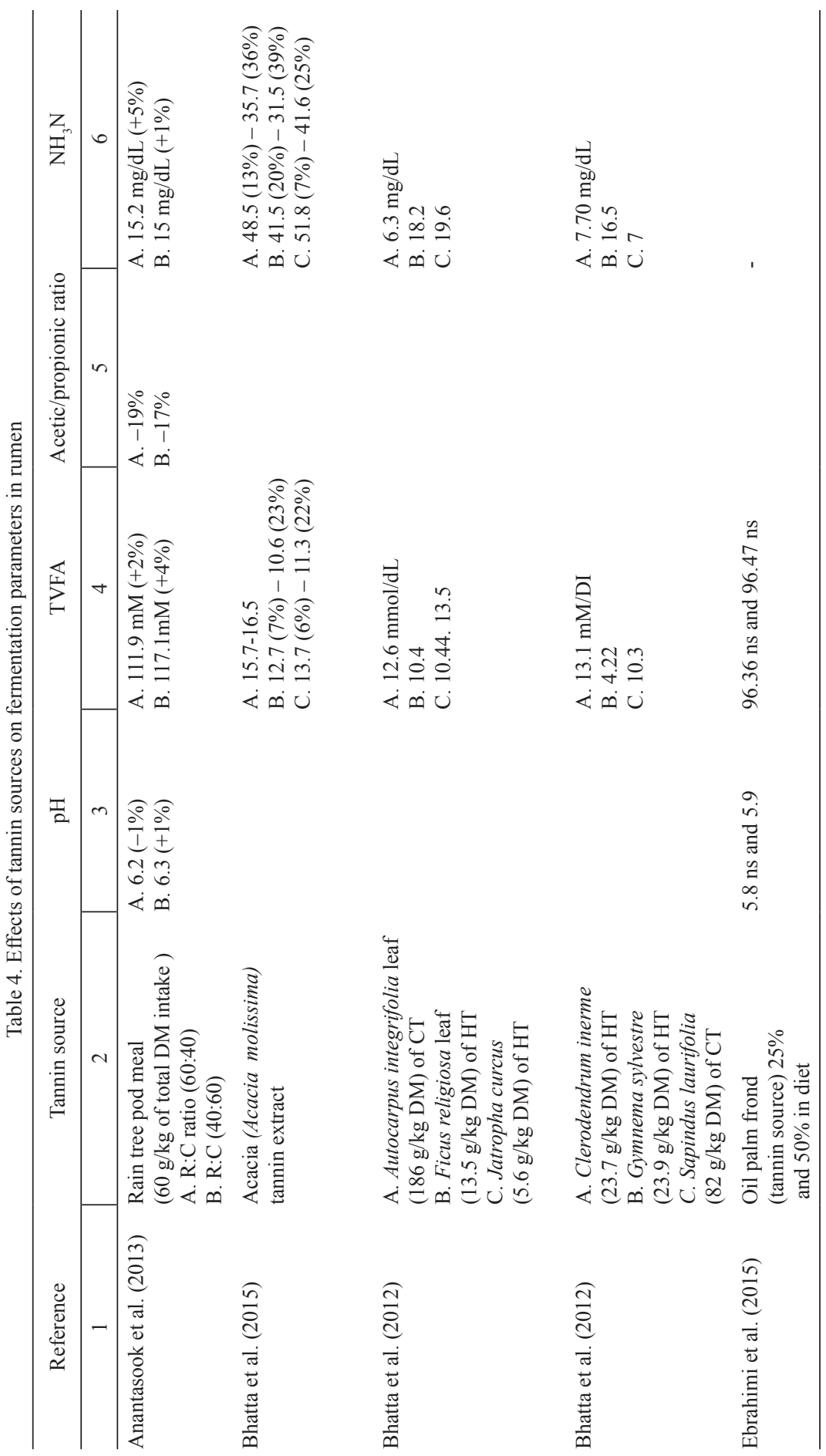




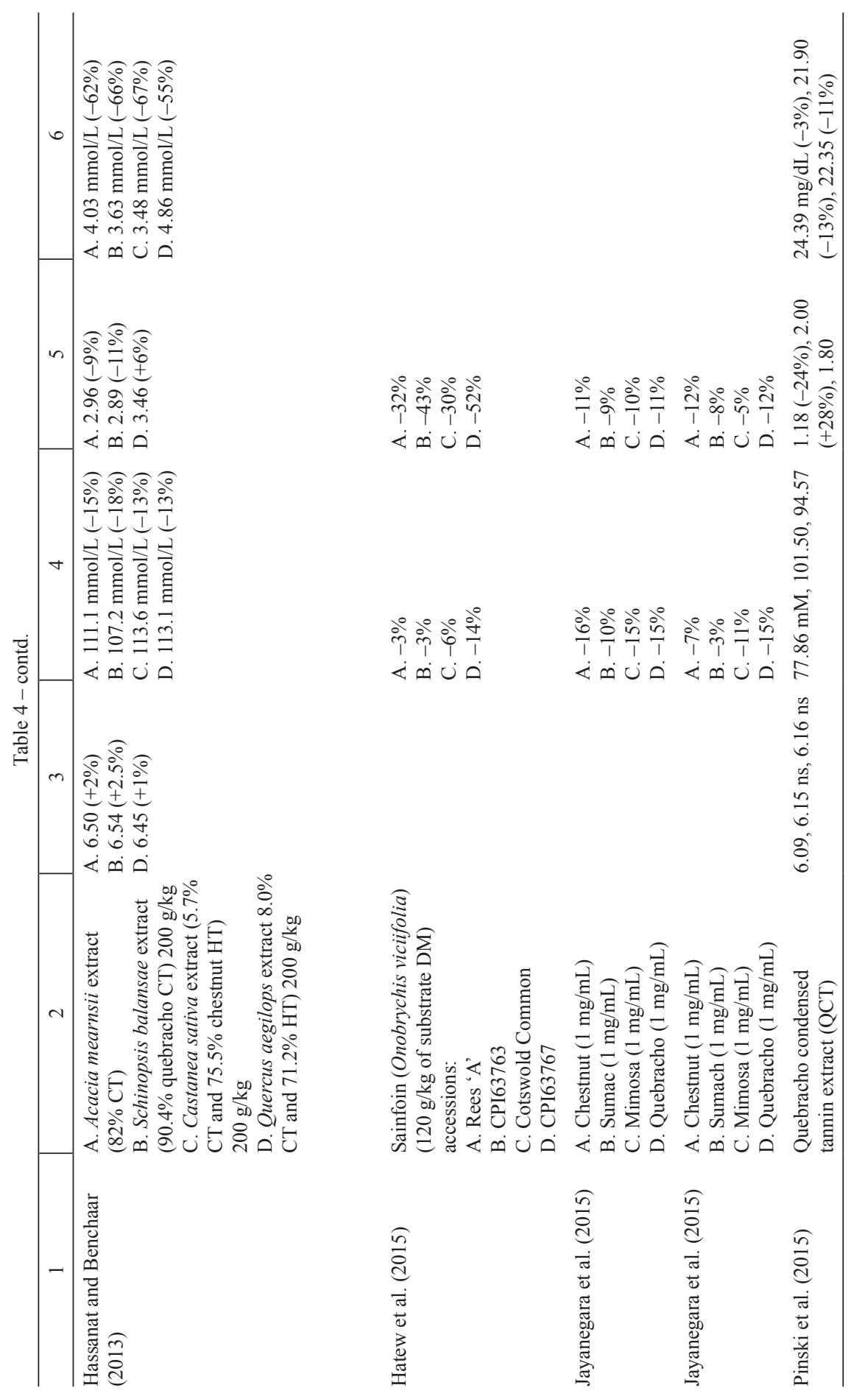




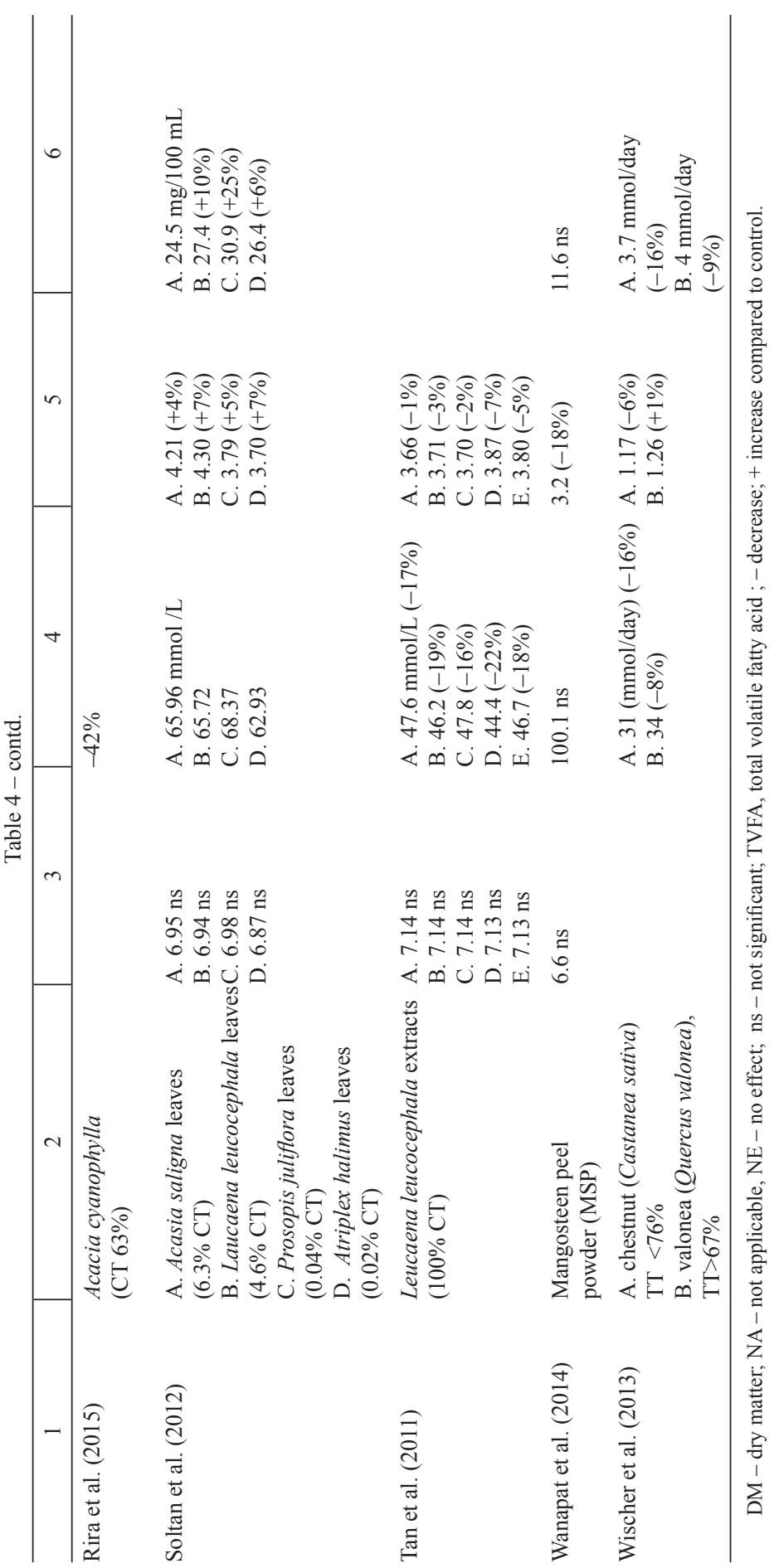




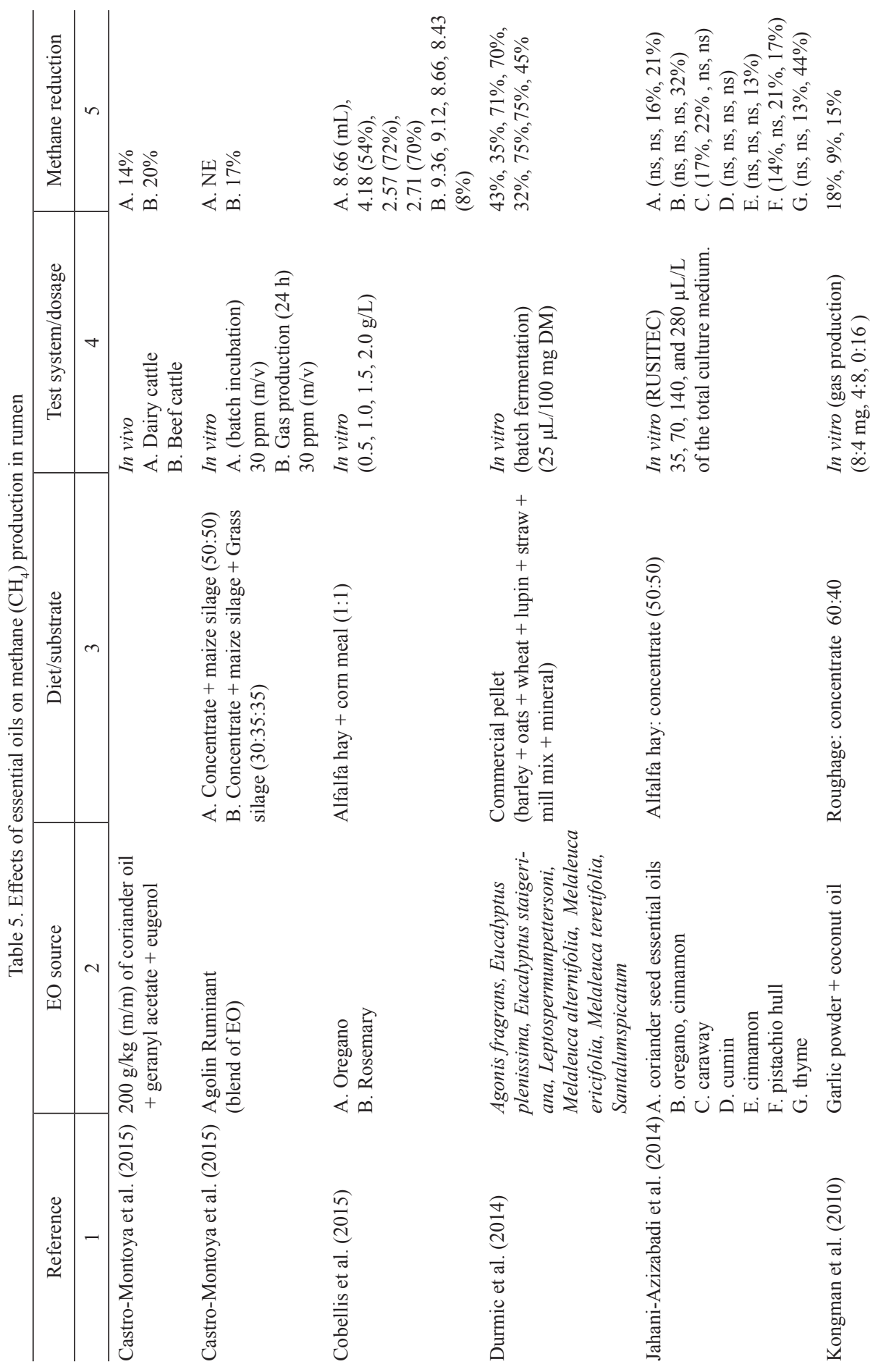



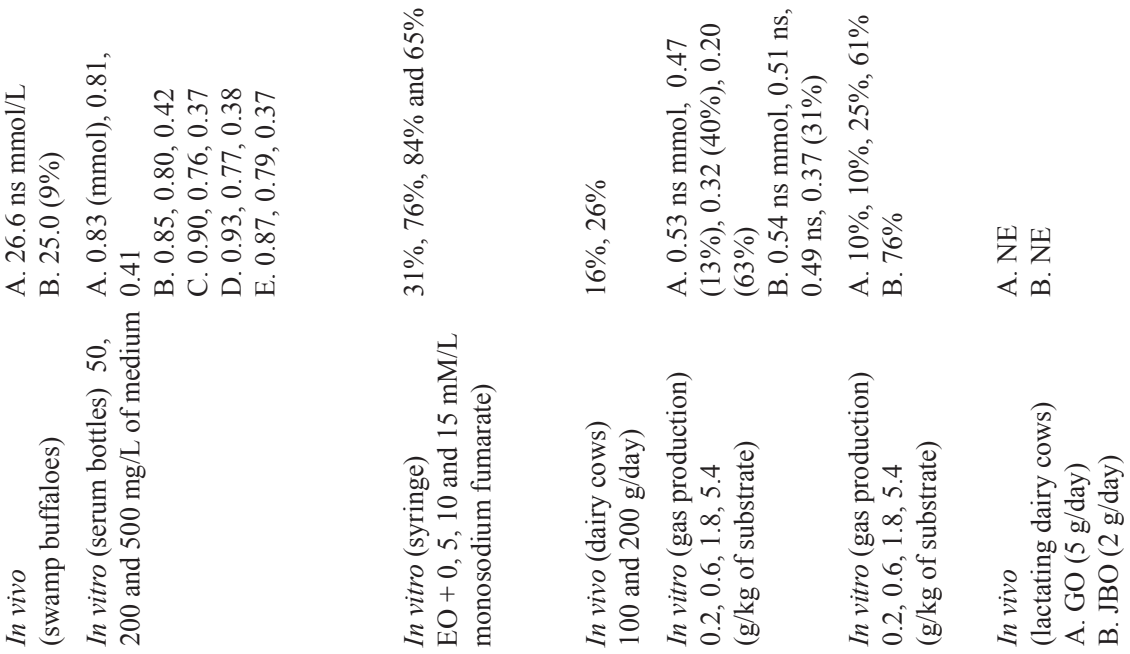

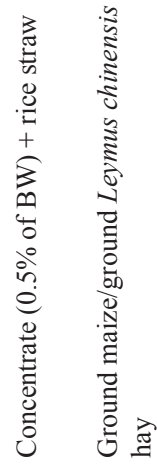
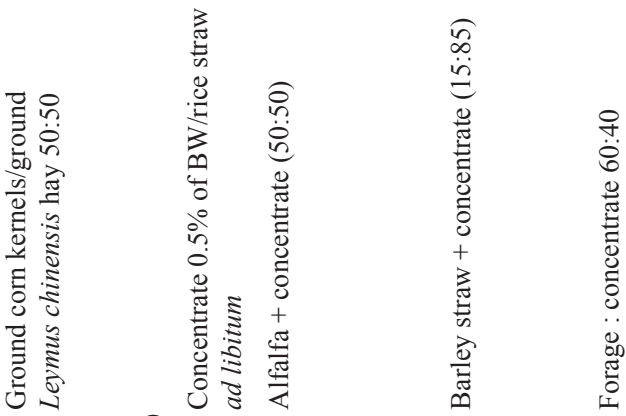

항

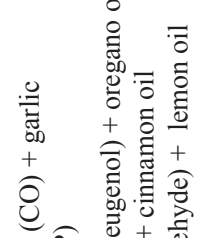
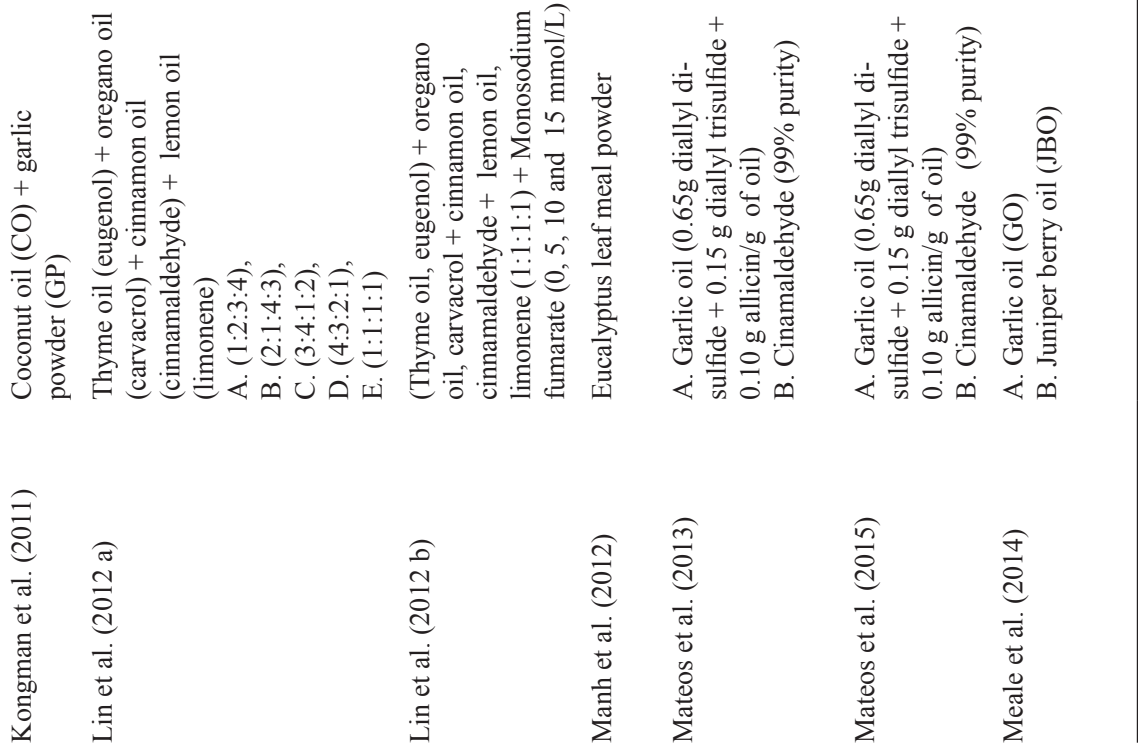


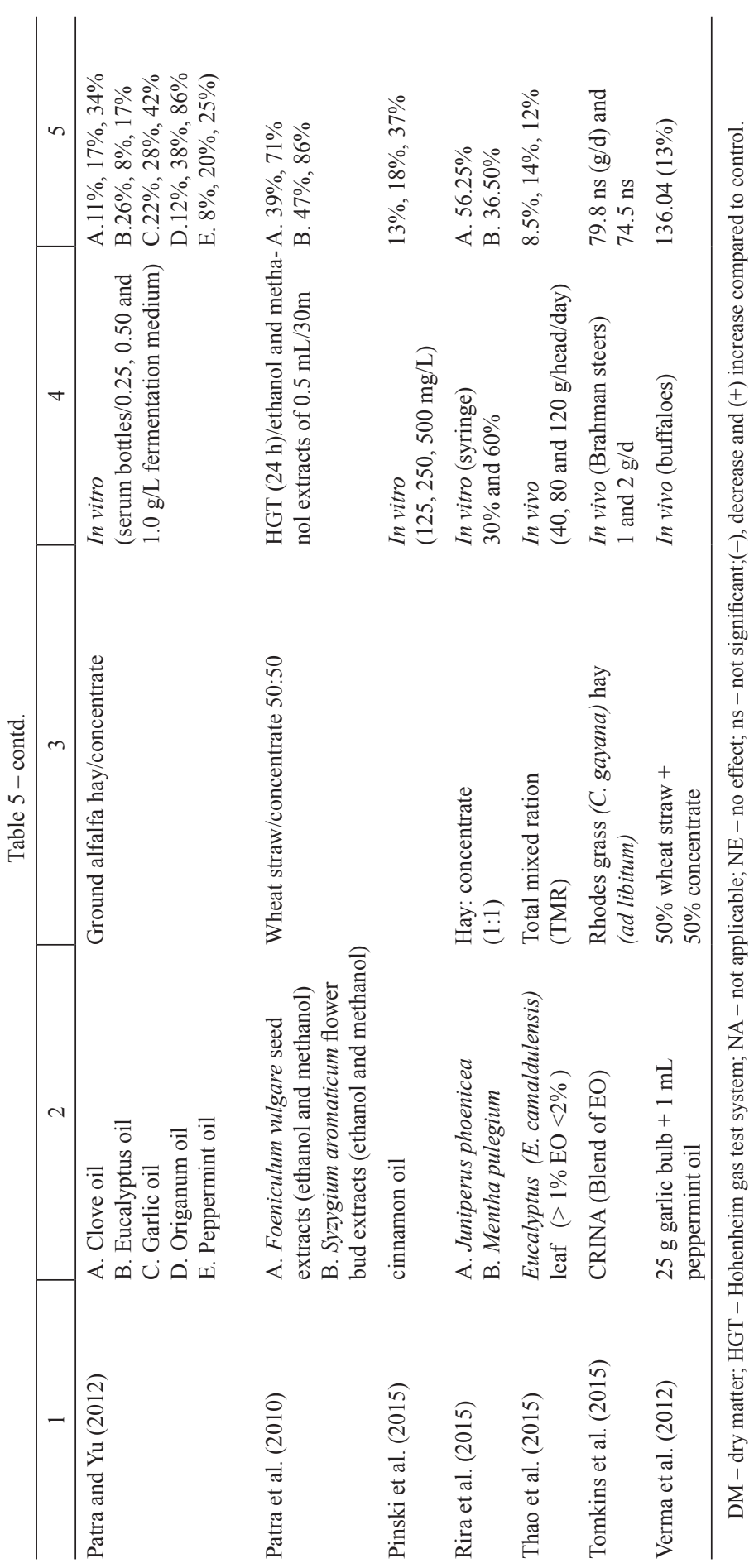




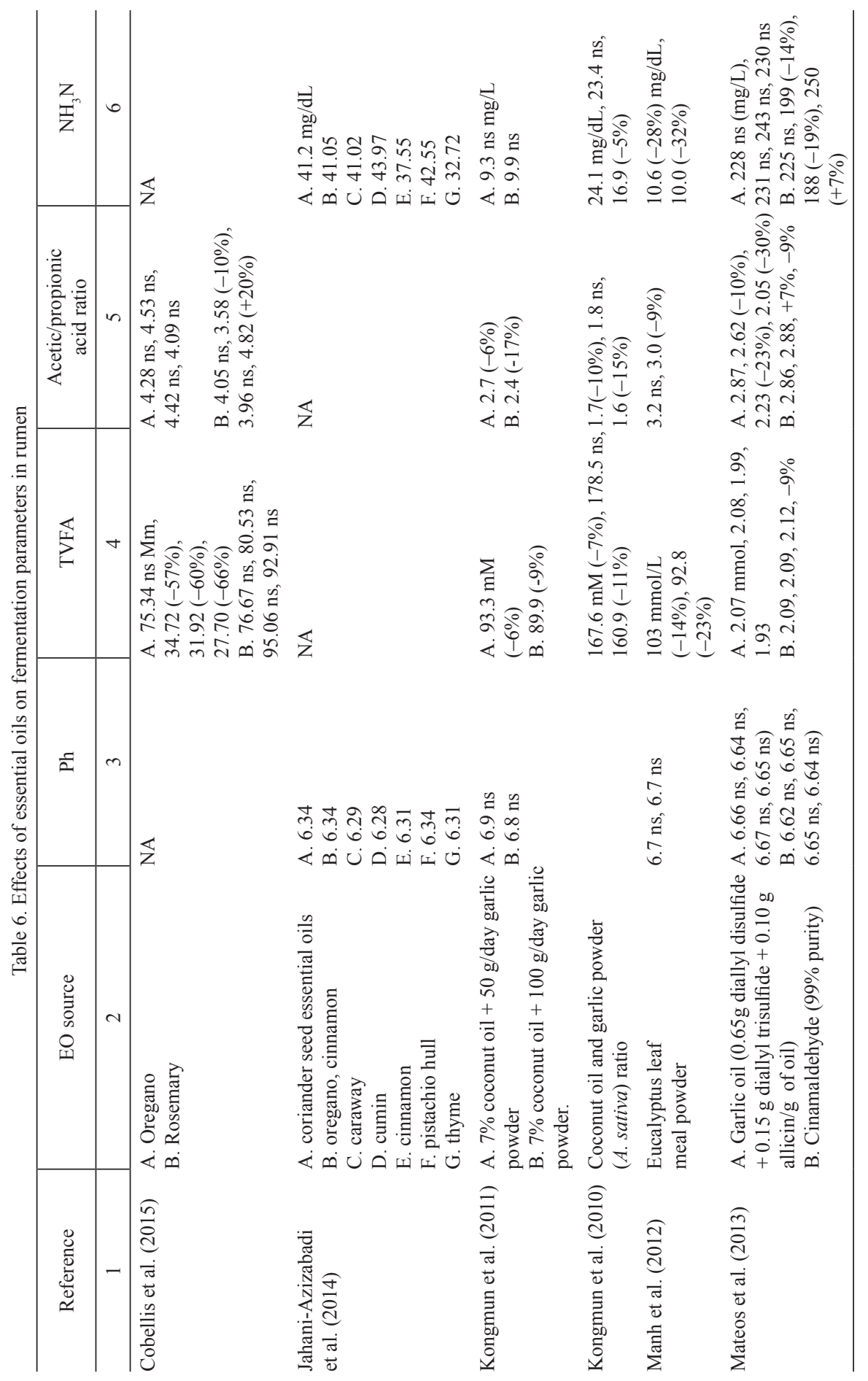




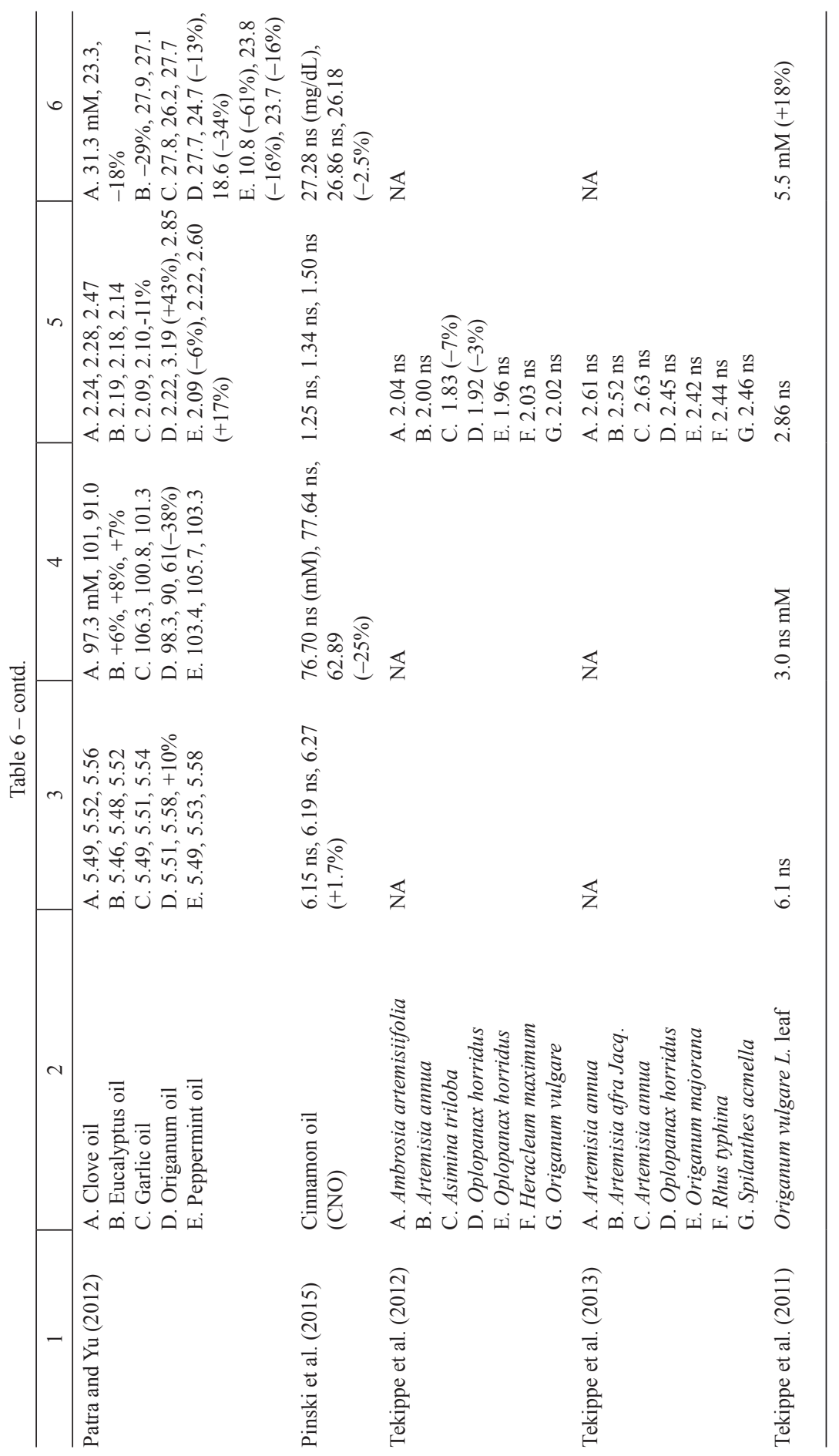




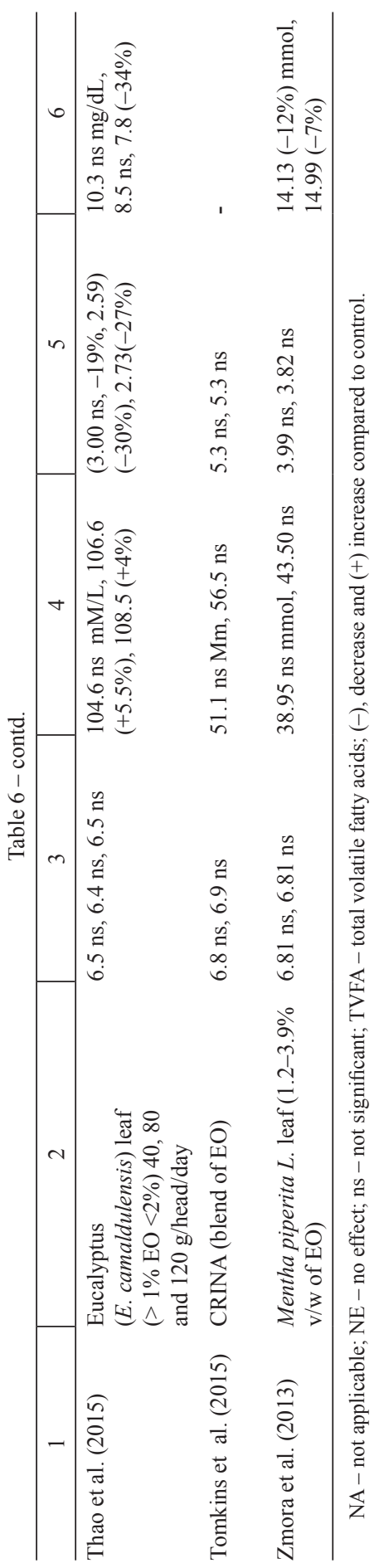




\section{Effect of tannins on rumen methanogenesis and fermentation characteristics}

Review of recent studies about the effects of tannin sources on rumen $\mathrm{CH}_{4}$ and fermentation parameters are shown in Tables 3 and 4, respectively. Tannins as a class of PSM could be divided into two groups based on chemical structure, which are hydrolysable tannins (HT) and condensed tannins (CT) (Goel and Makkar, 2012). Many factors like tannin type and plant source may influence results derived from the effect of tannin on methanogenesis (Goel and Makkar, 2012). Bouchard et al. (2013) indicated that beneficial effects of CT on enteric $\mathrm{CH}_{4}$ formation typically occur at dietary concentrations between 20 and $40 \mathrm{~g} \mathrm{CT} / \mathrm{kg}$ DM. However, Bueno et al. (2015) showed the lack of tannin effect on $\mathrm{CH}_{4}$ emissions in their studies. In spite of the fact that anti-methanogenic activity of phenolic compounds has been consistently demonstrated in several in vitro and in vivo studies, their effectiveness usually depends on the species of microorganisms and the concentration, type or source of CT (Patra and Saxena, 2011). In contrast to the former study, Bhatta et al. (2013) and Anantasook et al. (2014) reported that the ruminal $\mathrm{CH}_{4}$ concentration was reduced by tannin addition. Inoculum from different domesticated ruminant species has unequal rumen fermentation and degradability as a result of differing microbial diversity due to their respective feeding strategies behavior. Rumen fluid from bovines emits more $\mathrm{CH}_{4}$ than from small ruminants, when measured on a degraded organic matter basis. Bhatta et al. (2015) introduced PSM such as tannins as rumen modifiers because these compounds are natural products, which are generally accepted as environmentally safe and friendly in food production systems. It should be noted that not all types of tannins produce beneficial nutritional and environmental responses (Bhatta et al., 2014). Generally, tannins with low molecular weight showed greater inhibitory effects on rumen microbes, because of their higher protein-precipitating capacities than high molecular weight polymeric tannins (Bhatta et al., 2014).

Recently, it was also confirmed that samples containing both HT plus CT were more effective in reducing in vitro $\mathrm{CH}_{4}$ production than those containing only HT (Bhatta et al., 2012). Moreover, earlier study had shown that phenolic fractions present in tannin extracts were more effective than leaves containing tannins (Bhatta et al., 2009). Bhatta et al. (2014) declared that tannins can directly suppress methanogenesis by affecting rumen archaea and not by defaunation (removal of protozoa) per se. Protozoa can synergistically provide $\mathrm{H}_{2}$ as a source of electrons to the methanogens, and hence, antiprotozoal effects of tannins would be expected to decrease $\mathrm{CH}_{4}$ production by methanogens attached to protozoa. The effects of HT and CT may be different on ruminal ciliated protozoa, with HT generally being less inhibitory against protozoa than CT (Sliwinski et al., 2002). Pinski et al. (2015) concluded that addition of CT at concentration less than $50 \mathrm{~g} / \mathrm{kg}$ of DM did not adversely affect ruminal fermentation parameters. Beauchemin and McGinn (2007) also did not observe any reduction in $\mathrm{CH}_{4}$ production by feeding quebracho tannin extract up to $2 \%$ $(1.8 \% \mathrm{CT})$ of the dietary DM. However, a meta-analysis study by Jayanegara et al. (2012) concluded that increasing tannin concentrations (up to $177 \mathrm{~g} / \mathrm{kg}$ ) reduced $\mathrm{CH}_{4}$ production in vitro and in vivo. This discrepancy may be related to several factors such as supplement source, dose level, diet composition and the period of adaptation to the product. It is known that tannins reduce degradation of dietary protein in the 
rumen by forming protein-tannin complexes or the inhibition of the activities of the protease enzyme by tannin (Hatew et al., 2015). In an in vitro gas production test, supplementation of Acacia cyanophylla (containing 63\% of CT) at $60 \%$ and $30 \%$ resulted in $37.5 \%$ and $56.25 \%$ lower $\mathrm{CH}_{4}$, respectively (Rira et al., 2015). The results were attributed to the high CT content in Acacia cyanophylla which had been reported to be toxic for rumen microbial population, especially ciliate protozoa, fiber degrading microbes and methanogens (Kamra et al., 2006). In addition, the inhibition of $\mathrm{CH}_{4}$ production was accompanied by alteration in total volatile fatty acid profile and the acetate/propionate ratio through an increase in the concentration of propionate with Acacia cyanophylla supplementation. Jayanegara et al. (2015) reported that all the purified tannins (chestnut, sumac, mimosa and quebracho) at concentration of $1 \mathrm{mg} / \mathrm{mL}$ of rumen liquid were able to decrease ruminal $\mathrm{CH}_{4}$ emissions in vitro, and confirmed their previous results obtained about the inhibitory effect of tannins on rumen methanogenesis (Jayanegara et al., 2011, 2012 and 2013). Moreover, a meta-analysis study concluded that increasing tannin concentration ( 0 to $177 \mathrm{~g} / \mathrm{kg}$ ) reduced $\mathrm{CH}_{4}$ production in vitro and in vivo (Jayanegara et al., 2011).

Jayanegara et al. (2015) proposed two inhibitory mechanisms of tannins on $\mathrm{CH}_{4}$ emission from ruminants; (1) through reduction in fibre digestion, which decreases $\mathrm{H}_{2}$ production, and (2) through inhibition of the growth of methanogens. Tan et al. (2011) reported that CT at a relatively low level of $15 \mathrm{mg} / 500 \mathrm{mg}$ DM of CT, reduced $\mathrm{CH}_{4}$ production, decreased methanogen and protozoal populations and reduced nitrogen disappearance with only $7 \%$ reduction in dry matter digestibility. An in vitro study showed that $50 \mathrm{~g} / \mathrm{kg}$ dietary HT from chestnut or CT from acacia reduced $\mathrm{CH}_{4}$ production and ruminal protein degradation, but with a slight negative impact on total VFA concentration (Hassanat and Benchaar, 2013). Hassanat and Benchaar (2013) also reported up to the $40 \%$ reduction of $\mathrm{CH}_{4}$ production compared with control when the substrate was incubated with CT at $\geq 100 \mathrm{~g} / \mathrm{kg}$ with minimum detrimental effects on the efficiency of ruminal fermentation. They concluded that tannin sources could affect rumen methanogenesis without affecting other fermentation parameters and their impacts on rumen fermentation varies according to their type, source and concentration.

\section{Effect of essential oils on rumen methanogenesis and fermentation charac- teristics}

Review of recent studies about the effects of EO sources on rumen $\mathrm{CH}_{4}$ and fermentation parameters are shown in Table 5 and 6, respectively. EO consist of volatile constituents of terpenoid or non-terpenoid origin (Rira et al., 2015). Under this group, hundreds of large or small molecules can be present, consisting of hydrocarbons and their oxygenated derivatives. EO are known for their antimicrobial activity and are commonly used for the treatment of microbial infections (Rira et al., 2015). Conflicting results have been reported on the effects of EO on rumen methanogenesis. Rumen $\mathrm{CH}_{4}$ production reduction has been observed in response to EO supplements. Tekippe et al. (2012) screened among a collection of 100 EO and plants which were naturalized to, or successfully grown in North America and identified that three EO from Anethum graveolens (dill weed), Lavandula latifolia, 
and Ocimum basilicum and one plant sample (Origanum vulgare) with a potential for reducing $\mathrm{CH}_{4}$ production in vitro. Concentration of $\mathrm{NH}_{3} \mathrm{~N}$ was also very low at the end of the incubation for both EO and plant samples. Castro-Montoya et al. (2015) reported that the blend of EO tended to decrease daily $\mathrm{CH}_{4}$ emissions from dairy and the decrease was sustained for the six weeks of supplementation. In previous studies with other EO sources, in vitro $\mathrm{CH}_{4}$ inhibition was achieved only at extremely high concentrations; for example, Evans and Martin (2000) found that after $24 \mathrm{~h}$ thymol strongly inhibited in vitro $\mathrm{CH}_{4}$ production when added at a concentration of $400 \mathrm{ppm}$, but production of acetate and propionate strongly decreased. When thymol was incubated at a concentration of 200 ppm or lower, there were no effects on $\mathrm{CH}_{4}$, acetate and propionate production. Tomkins et al. (2015) showed that administration of daily CRINA (commercially made with blend of EO) into the rumen had a significant effect on rumen fermentation and decreased enteric methanogenesis when used at rates of 1 or $2 \mathrm{~g} / \mathrm{d}$. Similarly, Busquet et al. (2005) found that garlic oil and diallyl disulfide decreased in vitro $\mathrm{CH}_{4}$ production and total VFA production when applied at a concentration of $300 \mathrm{ppm}$. However, lower concentrations (30 ppm) of both EO showed no negative effect on fermentation parameters.

Cobellis et al. (2015) concluded that the effects of EO are due to their antimicrobial activity against ruminal microorganisms such as methanogenic archaea and hyper-ammonia-producing bacteria. However, EO also showed adverse effects on fiber digestion. The effect of $\mathrm{EO}$ in reducing in vitro $\mathrm{CH}_{4}$ production through a direct inhibition of methanogenic archaea and/or an indirect depression of some microbial metabolic processes involved in methanogenesis has been well documented (Rira et al., 2015). Patra and Yu (2012) found a decrease in the abundance of rumen archaea and protozoa by all the tested EO (clove, eucalyptus, garlic, oregano and peppermint) but also in that of cellulolytic bacteria. Total VFA concentration was also markedly reduced by oregano EO doses. In a similar study, Cardozo et al. (2004) found that the effects of some EO on rumen VFA profiles were more pronounced at low rumen $\mathrm{pH}$. They also suggested that $\mathrm{pH}$ is able to affect dissociated or undissociated status of EO molecules. The results of the proposed investigation showed that oregano EO, at the highest concentration, was a potent inhibitor of ruminal $\mathrm{CH}_{4}$ and $\mathrm{NH}_{3} \mathrm{~N}$ production mostly due to the antimicrobial properties of carvacrol, its major compound. Pinski et al. (2015) showed that except for cinnamon oil, EO tested in the study had no effect on culture $\mathrm{CH}_{4}$ production. However, previous in vitro (Sallam et al., 2009) and in vivo (Manh et al., 2012) experiments have reported that eucalyptus oil decreases $\mathrm{CH}_{4}$ production. These inconsistencies might be related to differences in supplement source, dose level and diet composition.

\section{Conclusion and future directions}

A conclusion from the current review is that the effects of saponin, tannin and EO on ruminal fermentation are desirable if they improve fermentation characteristics such as increase VFA concentration, decrease $\mathrm{NH}_{3} \mathrm{~N}$ concentration and decrease $\mathrm{CH}_{4}$ production. However, a reduction in VFA production as a result of plant additive supplementation, even if accompanied by reductions in $\mathrm{CH}_{4}$ production, would generally be viewed to be nutritionally unfavorable. Moreover, the literature suggests 
that saponins mitigate methanogenesis mainly by reducing the number of protozoa, tannins especially condensed tannin both by reducing the number of protozoa and by a direct toxic effect on methanogens, whereas EO act mostly by a direct toxic effect on methanogens. Although a large number of phytochemicals (e.g. saponins, tannins and essential oils) have been investigated for their $\mathrm{CH}_{4}$ reduction potential, there have not yet been major breakthroughs that could be applied in practice. Therefore, the future challenge will be to identify cost-effective PSM components which favorably alter ruminal fermentation by decreasing $\mathrm{CH}_{4}$ production without reducing total VFA concentrations.

\section{Acknowledgments}

The authors are thankful to the Faculty of Veterinary Medicine, Universiti Putra Malaysia.

\section{References}

A n a n t a s o o k N., Wa n a pat M., Ch e rd th ong A. (2014). Manipulation of ruminal fermentation and methane production by supplementation of rain tree pod meal containing tannins and saponins in growing dairy steers. J. Anim. Physiol. Anim. Nutri., 98: 50-55.

B e a u ch e min K.A., M c Gin n S. (2007). Methane emissions from beef cattle: effects of fumaric acid, essential oil, and canola oil. J. Anim. Sci., 84: 1489.

Bharathidhasan A., Viswanathan K., Balakrishnan V., Valli C., Ramesh S., S e n thil k u m a r S.M.R. (2013). Effects of Purified Saponin on Rumen Methanogenesis and Rumen Fermentation Characteristics Studied Using In Vitro Gas Production Technique. Inter. J. Vet. Sci., 2: 44-49.

Bhatta R., Uyeno Y., Tajima K., Takenaka A., Yabumoto Y., Nonaka I., Enishi O., Kurihara M. (2009). Difference in the nature of tannins on in vitro ruminal methane and volatile fatty acid production, and methanogenic archaea and protozoal populations. J. Dairy Sci., 92: 5512-5522.

B h a t t a R., S a r a van an M., B a r u a h L., S a m p a th K. (2012). Nutrient content, in vitro ruminal fermentation characteristics and methane reduction potential of tropical tannin-containing leaves. J. Sci. Food Agri., 92: 2929-2935.

Bhat ta R., S a ravanan M., B aruah L., S a mpath K.T., Pras ad C.S. (2013 a). Effect of plant secondary compounds on in vitro methane, ammonia production and ruminal protozoa population. J. Appl. Microbiol., 115: 455-465.

Bhatta R., B aruah L., S aravanan M., Suresh K.P., S a mpath K.T. (2013 b). Effect of medicinal and aromatic plants on rumen fermentation, protozoa population and methanogenesis in vitro. J. Anim. Physiol. Anim. Nutri., 97: 446-456.

B hat t a R., S a r a van a n M., B a ru a h L., P r a s a d C.S. (2015). Effects of graded levels of tannincontaining tropical tree leaves on in vitro rumen fermentation, total protozoa and methane production. J. Appl. Microbiol., 118: 557-564.

B od a s R., Prieto a N., García-Gonzále zb R., Andrés a S., Giráld e za F.J., López S. (2012). Manipulation of rumen fermentation and methane production with plant secondary metabolites. Anim. Feed Sci. Technol., 176: 78 -93.

B ouchard K., Wittenberg K.M., Legesse G., Krause D.O., Khafipour E., Buck l e y K.E., O m in s k i K.H. (2013). Comparison of feed intake, body weight gain, enteric methane emission and relative abundance of rumen microbes in steers fed sainfoin and lucerne silages under western Canadian conditions. Grass Forage Sci., 70: 116-129.

Bueno C., B randi R.A., Franzolina A., B enete G., Fagundes G.M., Abdalla A.L., L ouvandini H., Muir J.P. (2015). In vitro methane production and tolerance to condensed tannins in five ruminant species. Anim. Feed Sci. Technol., 205: 1-9. 
B us quet M., Cals a miglia S., Ferret A., Ka mel C. (2006). Plant extracts affect in vitro rumen microbial fermentation. J. Dairy Sci., 89: 761-771.

Card ozo P.W., C a ls a migli a S., Ferret A., K a m el C. (2004). Effects of natural plant extracts on ruminal protein degradation and fermentation profiles in continuous culture. J. Anim. Sci., 82: $3230-3236$.

Castro-Mon to y a J., P e iren N., C on e J.W., Z w e ife B., Fi e ve z V., De C a m peneere S. (2015). In vivo and in vitro effects of a blend of essential oils on rumen methane mitigation. Livest. Sci., 180: 134-142.

Chwalek M., Lalun N., B obichon H., Ple K., Voutquenne-Nazabadioko L. (2006). Structure-activity relationships of some hederagenin diglycosides: Haemolysis, cytotoxicity and apoptosis induction. Biochim. Biophys. Acta, 1760: 1418-1427.

Cieslak A., Szumacher-Strabel S., Oleszek W. (2013). Plant components with specific activities against rumen methanogens. Anim., 7: 253-265.

Cobellis G., Petrozzi A., Forte C., Acuti G., Orrù M., Marcotullio M.C. (2015). Evaluation of the effects of mitigation on methane and ammonia production by using Origanum vulgare L. and Rosmarinus officinalis L. essential oils on in vitro rumen fermentation systems. Sustainability,7:12856-12869.

Durmic Z., Moate P.J., Eckard R., Revel1 D.K., Williams R., Vercoe P.E. (2014). In vitro screening of selected feed additives, plant essential oils and plant extracts for rumen methane mitigation. J. Sci. Food Agr., 94: 1191-1196.

Ebrahimi M., Raji on M.A., Meng G.Y., Shokryzadan P., S a zili A.Q., Jahromi M.F. (2015). Feeding Oil Palm (Elaeis Guineensis, Jacq.) Fronds Alters Rumen Protozoal Population and Ruminal Fermentation Pattern in Goats. J. Anim. Sci., 14, article 3877, https://doi.org/10.4081/ ijas.2015.3877.

Evans J.D., Martin S.A. (2000). Effects of thymol on ruminal microorganisms. Curr. Microbiol., 41: $336-340$.

F e ng Z.H., C a o Y.F., G a o Y.X., L i Q.F., L i J.G. (2012). Effect of Gross Saponin of Tribulus terrestris on Ruminal Fermentation and Methane Production in vitro. J. Anim. Vet. Ad., 11: 2121-2125.

Fra n c is G., K e re m Z., M a k k a r H.P.S., B e c k e r K. (2002). The biological action of saponins in animal systems: a review. Br. J. Nutr., 88: 587-605.

G o el G., Makkar H.P.S. (2012). Methane mitigation from ruminants using tannins and saponins. Trop. Anim. Health Prod., 4: 729-739.

Gu o Y.Q., Li u J.X., Lu Y., Z hu W.Y., D e n m a n S.E., M c S w e e n e y C.S. (2008). Effect of tea saponin on methanogenesis, microbial community structure and expression of mcrA gene, in cultures of rumen microorganisms. Lett. Appl. Microbiol., 47: 421-426.

$\mathrm{H}$ a r tmann T. (2007). From waste products to ecochemicals: fifty years research of plant secondary metabolism. Phytochem., 68: 2831-2846.

H a s s a n a t F., B e n c h a a r C. (2013). Assessment of the effect of condensed (acacia and quebracho) and hydrolysable (chestnut and valonea) tannins on rumen fermentation and methane production in vitro. J. Sci. Food Agri., 93: 332-339.

Hatew B., Stringano E., Harvey M., Hendriks W.H., Hay ot C., Smith C., Pelli k a a $\mathrm{n}$ W. (2015). Impact of variation in structure of condensed tannins from sainfoin (Onobrychis viciifolia) on in vitro ruminal methane production and fermentation characteristics. J. Anim. Physiol. Anim. Nutri., DOI: 10.1111/jpn.12336.

H u W.L., L i u J.X., Ye J.A., W u Y.M., G u o Y.Q. (2005). Effect of tea saponin on rumen fermentation in vitro. Anim. Feed Sci. Technol., 120: 333-339.

J a fari S., Goh Y.M., R a j i o n M.A., J a hromi M.F., Ebrahimi M. (2016 a). Ruminal methanogenesis and biohydrogenation reduction potential of papaya (Carica papaya) leaf: an in vitro study. It. J. Anim. Sci., 15: 157-165.

J a fari S., Goh Y.M., Raj i on M.A., Jahromi M.F., Ebrahimi M. (2016 b). Manipulation of rumen microbial fermentation by polyphenol rich solvent fractions from papaya leaf to reduce green-house gas methane and biohydrogenation of C18 PUFA. J. Agri. Food Chem., DOI: 10.1021/acs.jafc.6b00846.

J a fari S., G oh Y.M., Raj i on M.A., J a hromi M.F., Ebrahimi M. (2016 c). Papaya (Carica papaya) leaf methanolic extract modulates in vitro rumen methanogenesis and rumen biohydrogenation. J. Anim. Sci., doi:10.1111/asj.12634. 
Jahani-Azizabadi H., Danesh Mesgaran M., Vakili A.R., Rezayazdi K. (2014). Effect of some plant essential oils on in vitro ruminal methane production and on fermentation characteristics of a mid-forage diet. J. Agr. Sci. Technol., 16: 1543-1554.

J a y a n e gar a A., G o el G., Makk a r H.P.S., B e cker K. (2010). Reduction in Methane Emissions from Ruminants by Plant Secondary Metabolites: Effects of Polyphenols and Saponins. Food Agri Org UN: $151-157$.

J a y a n e gar a A., Kre uze r M., W in a E., L e ib e r E. (2011). Significance of phenolic compounds in tropical forages for the ruminal bypass of polyunsaturated fatty acids and the appearance of biohydrogenation intermediates as examined in vitro. Anim. Prod. Sci., 51: 1127-1136.

J a y a negara A., Kreuzer M., Le iber F. (2012). Ruminal disappearance of polyunsaturated fatty acids and appearance of biohydrogenation products when incubating linseed oil with alpine forage plant species in vitro. Livest. Sci., 147: 104-112.

J a y a n e gar a A., I k h s a n T., T o h a r m a t T. (2013). Assessment of methane estimation from volatile fatty acid stoichiometry in the rumen in vitro. J. Indo. Trop. Anim. Agri., 38: 103-108.

J a y a n e gar a A., W i n a E., Ta k a h a s h i J. (2014). Meta-analysis on methane mitigating properties of saponin-rich sources in the rumen in vitro: influence of addition levels and plant sources. Asian-Australas. J. Anim. Sci., 27: 1426-1435.

J a y a n e gara A., G o e 1 G., Makk a r P.S.H., B e cker K. (2015). Divergence between purified hydrolysable and condensed tannin effects on methane emission, rumen fermentation and microbial population in vitro. Anim. Feed Sci. Technol., 209: 60-68.

Johnson K.A., Johnson D.E. (1995). Methane emissions from cattle. J. Anim. Sci., 73: 2483-2492.

K a m r a D.N., A g a rw a 1 N., Ch a u d h a ry L.C. (2006). Inhibition of ruminal methanogenesis by tropical plants containing secondary compounds. Intl. Congress Ser., 1293: 156-163.

Kongmun P., Wan a pat M., Pakdee P., Navanukraw C. (2010). Effect of coconut oil and garlic powder on in vitro fermentation using gas production technique. Livest. Sci., 127: 38-44.

Kongmun P., Wan a p a M., P a kd e e P., N avanukraw C., Yu Z. (2011). Manipulation of rumen fermentation and ecology of swamp buffalo by coconut oil and garlic powder supplementation. Livest. Sci., 135: 84-92.

Kumar S., Choudhury P.K., Carro M.D., Griffith G.W., Dagar S.S., Puniy a M., Calabro S., R avella S.R., Dhew a T., Upadhy a R.C., Sirohi S.K., Kundu S.S., Wa n a p a t M., P u n i y a A.K. (2013). New aspects and strategies for methane mitigation from ruminants. Appl. Microbiol. Biotechnol., DOI 10.1007/s00253-013-5365-0.

L i W., P ow e r s W. (2012). Effects of saponin extracts on air emissions from steers. J. Anim. Sci., 90: 4001-4013.

L in B., Lu Y., Wang J.H., Li ang Q., Li u J.X. (2012). Effects of combined essential oils along with fumarate on rumen fermentation and methane production in vitro. J. Anim. Feed Sci., 21: $198-210$.

Lin B., Wang JH., L u Y., Liang Q., Li u JX. (2013). In vitro rumen fermentation and methane production are influenced by active components of essential oils combined with fumarate. J. Anim. Physiol. Anim. Nutr., 97:1-9.

Manh N.S., Wanapat M., Uriyapongson S., Khejornsart P., Chanthakhoun V. (2012). Effect of eucalyptus (Camaldulensis) leaf meal powder on rumen fermentation characteristics in cattle fed on rice straw. Afri. J. Agri. Res., 7: 1997-2003.

M a o H.L., Wang J.K., Z h o u Y.Y., L i u JX. (2010). Effects of addition of tea saponins and soyabean oil on methane production, fermentation and microbial population in the rumen of growing lambs. Livest. Sci., 129: 56-62.

Mate os J., R anilla M.J., Tej id o M.L., S a ro C., K a me 1 C., Carro M.D. (2013). The influence of diet type (dairy versus intensive fattening) on the effectiveness of garlic oil and cinnamaldehyde to manipulate in vitro ruminal fermentation and methane production. Anim. Prod. Sci., 53: 299-307.

Mea le S.J., Chaves A.V., Mc A 11 is ter T.A., I wa a s A.D., Yang W.Z., B e n cha a C. (2014). Including essential oils in lactating dairy cow diets: effects on methane emissions. Anim. Prod. Sci., 54: 1215-1218.

Mihaela G., Criste A., Cocan D., Constantinescu R., Raducu C., Miresan V. 
(2014). Methane production in the rumen and its influence on global warming. Pro-Envir.,7: $64-70$.

Narvaez N., Wang Y., Mc A 11 is ter T. (2013). Effects of extracts of Humulus lupulus (hops) and Yucca schidigera applied alone or in combination with monensin on rumen fermentation and microbial populations in vitro. J. Sci. Food Agr., 93: 2517-2522.

Naumann H.D., Lambert B.D., Armstrong S.A., Fonseca M. A., Tedeschi L.O., M u i r J.P. (2015). Effect of replacing alfalfa with panicled-tick clover or sericea lespedeza in cornalfalfa-based substrates on in vitro ruminal methane production. J. Dairy Sci., 98: 3980-3987.

P a t r a A.K. (2012). Enteric methane mitigation technologies for ruminant livestock: a synthesis of current research and future directions. Envir. Monitor. Assess., 184: 1929-1952.

P a t r a A.K. (2014). A meta-analysis of the effect of dietary fat on enteric methane production, digestibility and rumen fermentation in sheep, and a comparison of these responses between cattle and sheep. Livest. Sci., 162: 97-103.

P a tr a M., S a x en a J. (2011). Exploitation of dietary tannins to improve rumen metabolism and ruminant nutrition. J. Food Agri., 91: 24-37.

P a tr a A.K., Yu Z. (2012). Effects of essential oils on methane production and fermentation by, and abundance and diversity of, rumen microbial populations. Appl. Environ. Microbiol., 78: 4271-4280.

Patra A.K., Yu Z. (2013). Effective reduction of enteric methane production by a combination of nitrate and saponin without adverse effect on feed degradability, fermentation, or bacterial and archaeal communities of the rumen. Bioresour. Technol., 148: 352-360.

P a tr a A.K., Yu G. (2014 a). Combinations of nitrate, saponin, and sulfate additively reduce methane production by rumen cultures in vitro while not adversely affecting feed digestion, fermentation or microbial communities. Bioresour. Technol., 155: 129-135.

P a tra A.K., Yu Z. (2014 b). Effects of vanillin, quillaja saponin, and essential oils on in vitro fermentation and protein degrading microorganisms of the rumen. Appl. Microbiol. Biotechnol., 98: 897-905.

P a t r a A.K., Yu Z. (2015). Effects of Adaptation of In vitro Rumen Culture to Garlic Oil, Nitrate, and Saponin and Their Combinations on Methanogenesis, Fermentation, and Abundances and Diversity of Microbial Populations. Front Microbiol., 6: 14-34.

P a tr a A.K., K a m r a D.N., A g a rw a 1 N. (2010). Effects of extracts of spices on rumen methanogenesis, enzyme activities and fermentation of feeds in vitro. J. Sci. Food Agr., 90: 511-520.

Patra A.K., S tivers on J., Yu Z. (2012). Effects of quillaja and yucca saponins on communities and select populations of ruminal bacteria and archaea, and fermentation in vitro. J. Appl. Microbiol., 113: 1329-1340.

P inski B., Günal M., A bu Ghazal eh AA. (2015). The effects of essential oil and condensed tannin on fermentation. Anim. Prod. Sci., http://dx.doi.org/10.1071/AN15069.

Rira M., Chentli A., B oufener S., B ous s eb ou H. (2015). Effects of plants containing secondary metabolites on ruminal methanogenesis of sheep in vitro. Energy Procedia., 74: 15-24.

S a 11 a m S.M.A., Bueno I.C.S., B rigide P., Godoy P.B., Vitti D.M.S.S., Abdalla A.L. (2009). Efficacy of eucalyptus oil on in vitro rumen fermentation and methane production. Options Mediterraneennes., 85: 267-272.

Sliwinski B.J., Carla R.S., Machmuller A., Kreuzer M. (2002). Efficacy of plant extracts rich in secondary constituents to modify rumen fermentation. Anim. Feed Sci. Technol., 101: 101-114.

Soltan Y.A., Morsy A.S., S allam S.M.A., Louvandini H., Abdalla A.L. (2012). Comparative in vitro evaluation of forage legumes (Prosopis, Acacia, Atriplex, and Leucaena) on ruminal fermentation and methanogenesis. J. Anim. Feed Sci., 21: 759-772.

Solt a n Y.A., Morsy A.S., S a 11 a m S.M.A., Luc as R.C., Louvandini H., Kreuzer M., A b d a 11 a A.L. (2013). Contribution of condensed tannins and mimosine to the methane mitigation caused by feeding Leucaena leucocephala. Arch. Anim. Nutr., 67: 169-184.

Tan H.Y., Si e o C.C., Abdullah N., Liang J.B., Huang X.D., Ho YW. (2011). Effects of condensed tannins from Leucaena on methane production, rumen fermentation and populations of methanogens and protozoa in vitro. Anim. Feed Sci. Technol., 169: 185-193.

Teki p pe J.A., Hristov A.N., Heyler K.S., Cas s idy T.W., Zheljazkov V.D., F erre i r a J.F.S., Karnati S.K., Varga G.A. (2011). Rumen fermentation and production effects of Origanum vulgare L. in lactating dairy cows. J. Dairy Sci., 94: 5065-5079. 
Tekippe J.A., Hristov A.N., Heyler K.S., Zheljazkov V.D., Ferreira J.F.S., Cantre 11 C.L., Varga G.A. (2012). Effects of plants and essential oils on ruminal in vitro batch culture methane production and fermentation. Can. J. Anim. Sci., 92: 395-408.

Tek ippe J.A., Tacoma R., Hristov A.N., Le e C., O.H.J., H e yler K.S., Cass idy T.W., Varga G.A., B ravo D. (2013). Effect of essential oils on ruminal fermentation and lactation performance of dairy cows. J. Dairy Sci., 96: 7892-7903.

Thao N.T., Wanapat M., Kang S., Cherdthong A. (2015). Effects of Supplementation of Eucalyptus (E. Camaldulensis) Leaf Meal on Feed Intake and Rumen Fermentation Efficiency in Swamp Buffaloes. Asian-Australas. J. Anim. Sci., 28: 951-957.

To m kin s N.W., D en man S.E., P ilajun R., Wan a pat M., M c S w e eney C.S., E 11 i ot t R. (2015). Manipulating rumen fermentation and methanogenesis using an essential oil and monensin in beef cattle fed a tropical grass hay. Anim. Feed Sci. Technol., 200: 25-34.

Verma V., Chaudhary L.C., A garwa 1 N., B ha r R., Ka m ra D.N. (2012). Effect of Feeding Mixture of Garlic Bulb and Peppermint Oil on Methane Emission, Rumen Fermentation and Microbial Profile in Buffaloes. Anim. Nutr. Feed Technol., 12: 157-164.

Wan a pat M., Chan tha khoun V., P hes a t cha K., K a ng S. (2014). Influence of mangosteen peel powder as a source of plant secondary compounds on rumen microorganisms, volatile fatty acids, methane and microbial protein synthesis in swamp buffaloes. Livest. Sci., 162: 126-133.

Wang X.F., Mao S.Y., Li u J.H., Zhang L.L., Cheng Y.F., Wand J., Zhu WY. (2011). Effect of the gynosaponin on methane production and microbe numbers in a fungus methanogen coculture. J. Anim. Feed Sci., 20: 272-284.

Wi s cher G., B o guhn J., S te ing a H., S chollen berger M., R o d e hut s c ord M. (2013). Effects of different tannin-rich extracts and rapeseed tannin monomers on methane formation and microbial protein synthesis in vitro. Animal, 7: 1796-1805.

Zhou C.S., Xia o W.J., Tan Z.L., Salem A.Z.M., Geng M.M., Tang S.X., Wang M., H a n X.F., K ang JH. (2012). Effects of dietary supplementation of tea saponins (Ilex kudingcha C.J.Tseng) on ruminal fermentation, digestibility and plasma antioxidant parameters in goats. Anim. Feed Sci. Technol., 176: 163-169.

Zhou Y.Y., Ma o H.L., Ji ang F., Wang J.K., Li u J.X., M c S w e e ne y C.S. (2011). Inhibition of rumen methanogenesis by tea saponins with reference to fermentation pattern and microbial communities in Hu sheep. Anim. Feed Sci. Technol., 166-167: 93-100.

Z mor a P., C i e s lak A.,P er s-Ka m c z y c E., Now ak A., S z c zechow iak J., S zum a cher- S tra bel M. (2013). Effect of Mentha piperita L. on in vitro rumen methanogenesis and fermentation. Acta Agr., 62: 46-52.

Received: 8 III 2018

Accepted: 27 VII 2018 